\title{
Effects of aromatase mutation (ArKO) on the sexual differentiation of kisspeptin neuronal numbers and their activation by same versus opposite sex urinary pheromones
}

\author{
Julie Bakker*, Sylvie Pierman, David González-Martínez \\ GIGA Neurosciences, University of Liège, B36 (1st floor). Avenue de l'Hopital, 1 4000, Liège, Belgium
}

\section{A R T I C L E I N F O}

\section{Article history:}

Received 17 July 2008

Revised 18 November 2009

Accepted 19 November 2009

Available online 27 November 2009

\section{Keywords:}

Estrogens

Kisspeptin

Odors

Aromatase knockout

Sexual differentiation

\begin{abstract}
A B S T R A C T
Pheromones have been shown to induce sexually dimorphic responses in LH secretion. Here we asked whether the sexually dimorphic population of kisspeptin neurons in the rostral periventricular area of the third ventricle (RP3V) could relay sexually dimorphic information from the olfactory systems to the GnRH system. Furthermore, we analyzed the effects of aromatase mutation (ArKO) and thus the role of estradiol on RP3V kisspeptin neuronal numbers and on the response of these kisspeptin neurons to same- versus opposite-sex urinary pheromones. Exposure to male but not female urinary odors induced Fos protein in kisspeptin neurons in the RP3V of female wildtype (WT) mice, suggesting that these kisspeptin neurons may be part of the neural circuitry that relays information from the olfactory brain to the GnRH system in a sexually dimorphic manner. Male pheromones induced Fos in kisspeptin neurons in ArKO females, albeit significantly less compared to WT females. The sexual differentiation of kisspeptin neuronal number was lost in ArKO mice, i.e. the number of kisspeptin-immunoreactive neurons in the RP3V of ArKO females was as low as in male mice, whereas male ArKO mice had somewhat increased numbers of kisspeptin neurons. These results suggest that the sex difference in kisspeptin neuronal number in WT mice reflects an organizational action of estradiol in females. By contrast, the ability of male urinary pheromones to activate kisspeptin neurons in WT females may not depend on the organizational action of estradiol since ArKO females still showed some Fos/kisspeptin co-activation.
\end{abstract}

(c) 2009 Published by Elsevier Inc.

\section{Introduction}

Pheromones affect several aspects of reproduction in mice, including the induction of sexual maturation (Lombardi and Vandenbergh, 1977), estrus synchronization (Whitten, 1959), and the initiation of a pregnancy block (Bruce, 1959; Lloyd-Thomas and Keverne, 1982). Indeed, it has been shown that pheromones activate olfactory structures, i.e., induce the expression of Fos protein, such as the peripheral vomeronasal organ (VNO) or the accessory olfactory bulb (AOB), and downstream target-sites (Pankevich et al., 2006; Kang et al., 2006; Dudley et al., 2001). Recently, two research groups have used different tracing approaches to show that the main olfactory epithelium and main olfactory bulb (MOB) project to and activate GnRH neurons (Boehm et al., 2005; Yoon et al., 2005). Boehm et al (2005) also showed that some of these neural projections are sexually dimorphic, such as the ones including the VMHvl and the PMV (ventrolateral part of the ventromedial hypothalamic nucleus and ventral part of the premammillary nucleus, respectively), brain areas that are important for the expression

\footnotetext{
* Corresponding author. Fax: +32 43665953.

E-mail address: j.bakker@ulg.ac.be (J. Bakker).
}

of sexual behavior (Meisel and Sachs, 1994; Pfaff et al., 1994; Simerly, 2002). By contrast, no evidence of sexually dimorphic projections was found between the olfactory bulb and the GnRH population in the preoptic area. This is remarkable since only pheromones from opposite sex conspecifics induce sexually dimorphic responses in GnRH neurons and consequently LH secretion. For instance, pheromones derived from female mice significantly increased the percentage of activated GnRH neurons (Yoon et al., 2005) and induced a rapid and large increase in LH release in males (Coquelin and Bronson, 1979; Bronson and Desjardins, 1982) whereas pheromones derived from male mice induced LH release in female mice (Bronson and Maruniak, 1976). So at present it remains unclear how pheromones induce a sexually dimorphic activation of the GnRH system and consequently LH release.

In recent years, the Kiss1 gene product, kisspeptin, has been proposed as an upstream regulator of the GnRH system as human patients did not enter into puberty due to a mutation in the GPR54 gene (de Roux et al., 2003), which encodes the kisspeptin receptor, named GPR54 (now named Kiss1r). Similar results were obtained in mice with a targeted disruption of the Kiss1 gene (d'Anglemont et al., 2007). Furthermore, kisspeptin is involved in integrating the positive feedback action of estrogens on the GnRH system in female mammals (Estrada et al., 2006; Adachi et al., 2007), whereas in male mammals, 
an injection of kisspeptin in discrete regions of the hypothalamus induced the release of LH (Patterson et al., 2006). Interestingly, kisspeptin expression is sexually dimorphic in rodent species, with females having a larger population of kisspeptin expressing neurons than males in the rostral periventricular area of the third ventricle (RP3V) (Clarkson and Herbison, 2006; Kauffman et al., 2007), suggesting that kisspeptin may play a sexually dimorphic role in controlling reproductive events. Due to this neural sexual differentiation and dimorphism, kisspeptin neurons in the RP3V could be part of the neural circuitry that relays sexually dimorphic information from the olfactory systems to the hypothalamic GnRH neurons. Therefore, in the present study, we determined whether pheromones are able to activate kisspeptin neurons in the RP3V of male and female mice in a sexually dimorphic manner. We used aromatase knockout (ArKO) mouse mice to determine whether these sexually dimorphic responses of kisspeptin neurons to pheromones reflect the developmental actions of estrogens in the central nervous system by comparing the number of kisspeptin neurons as well as its activation by pheromones in wild-type (WT) and ArKO mice of both sexes. ArKO mice have a targeted mutation in the Cyp19 gene that encodes the aromatase enzyme which catalyzes the final step in the biosynthesis of $C_{18}$ estrogens from $C_{19}$ steroids, indicating thus a complete absence of estrogens during embryonic and postnatal development. We have observed several changes in olfactory functioning in ArKO mice. For instance, male ArKO mice resembled WT females in their ability to respond to lower concentrations of urinary odors than male WT mice, suggesting that the observed sex difference among WT mice in urine attraction thresholds (Baum and Keverne, 2002) results from the perinatal actions of estrogens in the male nervous system (Pierman et al., 2006). By contrast, the processing of sexually relevant odors by the olfactory bulbs was not affected in ArKO mice of both sexes (Pierman et al., 2008). These results indicate that estrogens may be important for the integration of odors into the reproductive system and thus may be involved in the organization and activation of sexually dimorphic responses of the hypothalamic GnRH system to pheromones. All subjects were treated with estradiol benzoate in adulthood so that any differences between ArKO and WT mice in kisspeptin neuronal number or activation reflect a difference in estradiol signaling earlier in life.

\section{Materials and methods}

\section{Animals}

In the present study we used aromatase knock-out mice with a targeted disruption of exons 1 and 2 of the Cyp 19 gene (Honda et al., 1998). Heterozygous (HET) males and females of the C57BL/6J strain were bred to generate wild-type (WT) and knock-out (ArKO) offspring. Mice were genotyped by PCR analysis of tail DNA (Bakker et al., 2002a). All breeding and genotyping were performed at the GIGA Neurosciences (formerly known as Center for Cellular \& Molecular Neurobiology), University of Liège, Belgium. Food and water were always available ad libitum and the temperature was maintained at $22{ }^{\circ} \mathrm{C}$.

Adult WT and ArKO mice of both sexes were gonadectomized under general anesthesia through an intraperitoneal injection of a mixture of ketamine ( $80 \mathrm{mg} / \mathrm{kg}$ per mouse) and medetomidine (Domitor, Pfizer, $1 \mathrm{mg} / \mathrm{kg}$ per mouse). Mice received atipamezole (Antisedan, Pfizer, $4 \mathrm{mg} / \mathrm{kg}$ per mouse, subcutaneously) at the end of surgery in order to antagonize medetomidine-induced effects, thereby accelerating their recovery. Then mice were placed in individual cages and treated daily with estradiol benzoate (EB, $5 \mu \mathrm{g}$ in $0.05 \mathrm{ml}$ sesame oil/mouse) by subcutaneous injection in the neck at least 2 weeks before being exposed to odors. Males and females were housed in two separate rooms under a reversed light-dark cycle (12:12 light/dark). Subjects were gonadectomized and subsequently treated with estradiol in order to study the organizational and activational effects of estrogens on kisspeptin neurons. As previously shown by Fisher et al (1998), gonadally intact ArKO mice of both sexes lack detectable levels of estrogens as to be expected, but also show increased levels of testosterone, androstenedione, FSH and LH compared to WT animals. Therefore, to avoid confounding effects of these other hormones on kisspeptin expression in ArKO mice, all animals received the same estradiol treatment since we are primarily interested in the organizational role of this hormone. In that respect the ArKO mouse is unique in that they can be treated with estradiol at any time during their lifespan since they have functional estrogen receptors and thus this model can be used to distinguish between organizational and activational effects of estradiol on the brain. Finally, this estradiol treatment has shown to be effective to study the central processing of sexually relevant olfactory cues in mice (Pierman et al., 2008). All experiments were conducted in accordance with the guidelines set forth by the National Institutes of Health Guiding Principles for the Care and Use of Research Animals and were approved by the Ethical Committee for Animal Use of the University of Liège.

\section{Urine collection}

In the present study, we determined the ability of urinary odors that were applied directly onto their nose to activate kisspeptin neurons. We chose to apply the urine directly onto the nose instead of giving free access to the urine since we wanted to be sure that there would be no differences in activation due to differences in time spent investigating the urinary odors, since our previous studies (Bakker et al., 2002a,b; Pierman et al., 2006) showed that ArKO mice are less motivated to investigate sexually-relevant (opposite-sex) urinary odors. Furthermore, it has been shown that applying urine onto the nose directly activates both the main and the accessory olfactory system (Dudley et al., 2001; Kang et al., 2006; Pankevich et al., 2006) and by doing so we maximized the likelihood that any effect of the urinary pheromones on kisspeptin neurons would be seen.

Thus, urine was collected from 10 gonadally intact $C 57 \mathrm{BL} / 6 \mathrm{~J}$ males. Estrous female urine was collected from 10 ovariectomized C57BL/6J females which had an estradiol implant (diluted 1:1 with cholesterol; Bakker et al., 2002b) and which were injected with $500 \mu \mathrm{g}$ progesterone (P) 2-4 h prior to urine sampling. Urine was collected by holding the mouse by the scruff of the neck over a funnel, taking care that no fecal contamination of the urine occurred. In order to collect the urine, animals were habituated to be handled and urine was collected at different days during several weeks, but always at the same time during the day (early afternoon). Same urine stimulus samples were pooled and subsequently aliquoted in $500-\mu \mathrm{L}$ Eppendorf vials and stored at $-80{ }^{\circ} \mathrm{C}$ until use.

\section{Procedure for exposure to urine}

After 2 weeks of EB treatment with a daily injection of $5 \mu \mathrm{g}$ (dissolved in sesame oil), mice were trained daily for 1 week during the first hour of the dark phase of the light/dark cycle to the procedure used for urine exposure while continuing to receive EB treatment. Thus subjects were habituated to be taken out of their home cage and to receive $30 \mu \mathrm{l}$ of deionized water onto their nose before being placed back in their cage.

On the day of testing, subjects were divided into three different groups depending on the urinary odor that they were going to be exposed to. Group 1 was exposed to intact male urine (WT: 6 males and 6 females; ArKO: 6 females and 9 males), group 2 to estrous female urine (WT: 8 males and 6 females; ArKO: 6 of each sex) and group 3 was exposed to deionized water to serve as control (WT: 6 males and 8 females; ArKO: 6 of each sex). All animals were exposed to the odor stimulus during the first $3 \mathrm{~h}$ of the dark phase of the light/ dark cycle. 
Ninety minutes after urine exposure, animals were anesthetized with ketamine/ medetomidine and perfused transcardially with saline followed immediately by $4 \%$ cold paraformaldehyde. Brains were removed and postfixed in $4 \%$ paraformaldehyde for $2 \mathrm{~h}$. Then brains were cryoprotected in $30 \%$ sucrose/PBS solution and when sunk, frozen on dry ice and kept at $-80^{\circ} \mathrm{C}$. Cryostat (Leica CM1510 S) brain sections were cut coronally from the rostral telencephalon to the posterior hypothalamus making four sets of $30 \mu \mathrm{m}$ sections. Sections were saved in cryoprotectant solution and maintained at $-20{ }^{\circ} \mathrm{C}$ for later immunohistochemistry.

\section{Immunocytochemistry and data analysis}

To determine co-localization of Fos and kisspeptin neurons in the RP3V of WT and ArKO mice we performed a double labeling immunocytochemistry on the brain sections. Primary antibodies were specific to fos polyclonal antibody (pAb) (1:2000 sc-52 rabbit c-fos pAb, Santa Cruz Biotechnology Inc.) and kisspeptin (kisspeptin pAb, kisspeptin is a polypeptide derived from the Kiss-1 product; 1:20000 rabbit pAb, donated by Dr A Caraty (Franceschini et al., 2006).

For the double labeling immunocytochemistry sections were first washed in $0.1 \mathrm{M}$ PBS pH 7.4 (PBS), then the peroxidase activity was blocked in 1:4 Methanol:PBS solution with $3 \% \mathrm{H}_{2} \mathrm{O}_{2}$. Sections were permeabilized in PBS-0.1\% Triton-X100 (PBST) and then saturated in $5 \%$ Normal Goat Serum (NGS) in NGS-PBST. Immediately after this step, sections were incubated in diluted Fos Ab overnight. On the following day, sections were washed in PBST and incubated in a goat anti-rabbit biotinylated secondary Ab (Dako, Prod. Ref. B0432, $0.75 \mu \mathrm{g} / \mathrm{ml}$ PBST). Sections were then washed in PBST and incubated in the Vectastain Elite ABC Kit (Vector, Prod. Ref. PK6100). After development with the DAB Substrate Kit (Vector, SK-4100), in a black precipitate $\left(3,3^{\prime}\right.$-diaminobenzidine $\left.(\mathrm{DAB})+\mathrm{Ni}^{2+}\right)$, sections were washed thoroughly in PBS, re-fixed in 4\% paraformaldehyde and the residual peroxidase activity was blocked in 1:4 Methanol:PBS solution with $3 \% \mathrm{H}_{2} \mathrm{O}_{2}$. Sections were refixed in $4 \%$ paraformaldehyde in $0.1 \mathrm{M}$ PBS for $15 \mathrm{~min}$. Sections were then permeabilized and blocked in $5 \%$ NGS-PBST and incubated in kisspeptin primary antibody for $72 \mathrm{~h}$ at $4^{\circ}$. Similar secondary antibody and $\mathrm{ABC}$ incubation steps were then performed. The developing reaction used in this step was a DAB brown precipitate using the same kit. Once completed the ICC step, sections were mounted in Eukitt after being air-dried.

The specificity of the kisspeptin antibody has been validated previously (Gonzalez-Martinez et al., 2008; d'Anglemont et al., 2007). No significant kisspeptin immunoreactivity has been detected in mice lacking a functional Kiss-1 gene, in addition to other specificity controls done by Franceschini et al. (2006), such as testing the cross reactivity of various hypothalamic peptides by radioimmunoassay using iodinated kisspeptin. Furthermore, we have also tested the specificity of the antibody by pre-absorbing $1 \mu \mathrm{g}$ of antibody with $2 \mu \mathrm{g}$ of the polypeptide YNWNSFGLRY-NH2 corresponding to amino acid residues 43-52 of mouse metastin immunogen used for raising this antibody for $2 \mathrm{~h}$ at room temperature. This control has been done in adjacent sections and showed no labeling with the pre-absorbed antibody. The counting areas were limited to the RP3V where kisspeptin neurons were found to be activated, i.e. showing kisspeptin/Fos double-labeling. The counting was performed on kisspeptin neurons that were located within interaural: 4.06-3.94 mm and Bregma: 0.26-0.14 mm according to (Franlyn and Paxinos, 1997). Both hemispheres of four adjacent brain sections (with an interval of 60 micrometers between them) were counted in the RP3V.

\section{Statistical analysis}

Three-ways ANOVAs with sex, genotype and type of urine exposure (water, intact male or estrous female urine) as independent factors and the number of kisspeptin expressing neurons in the RP3V as dependent measure were conducted. The same statistical analysis was then conducted on the percentage of kisspeptin neurons coexpressing Fos immunoreactivity. When appropriate, all ANOVAs were followed by Fisher Least Signification Difference (LSD) post hoc comparisons. Only effects detected by the ANOVAs with $P$-value lower than 0.05 are mentioned as significant in Results.

\section{Results}

Number of kisspeptin expressing neurons

A sex difference was observed in WT mice with females having a greater number of kisspeptin-expressing neurons in the RP3V than males (Fig. 1). The number of kisspeptin neurons was dramatically reduced in ArKO mice, especially in female ArKO mice, whereas male ArKO mice had somewhat increased numbers. Indeed, statistical analysis revealed a significant effect of $\operatorname{sex}(F(1,75)=115.71$, $P=0.0001)$ and genotype $(F(1,75)=54.64, P=0.0002)$ as well as a significant sex by genotype interaction $(F(1,75)=105.27, P=$ $0.0001)$. Since the type of urine exposure did not influence the number of kisspeptin expressing cells observed in the different groups of mice (none of the statistical effects involving this factor was significant), the results in Fig. 1 present the number of kisspeptin expressing neurons in the RP3V of WT and ArKO mice of both sexes independent of type of urine exposure. Furthermore, post hoc analysis showed that WT females had significantly more kisspeptin neurons in the RP3V than WT males (WT males vs. females: $P=0.0001$ ) and that this sex difference was completely absent in ArKO mice (ArKO males vs. females: $P=0.73$ ). Indeed, the number of kisspeptin neurons was dramatically reduced in the RP3V of ArKO females in comparison between wild-type female (WT vs. ArKO females: $P=0.0001$ ) and significantly higher in ArKO males versus WT males (WT vs. ArKO males: $P=0.042$ ).

\section{Percentage of kisspeptin neurons co-expressing Fos immunoreactivity}

Exposure to urine derived from intact males activated an average of $38.4 \%$ of kisspeptin expressing neurons in the RP3V of WT females (depicted in Fig. 2C) whereas exposure to water (depicted in Fig. 2A) or urine derived from estrous females did not (Fig. 3). This pattern of activation by male urine was reduced in ArKO females, where only $17.7 \%$ of kisspeptin expressing neurons were co-labeled with Fos immunoreactivity (Fig. 3 and depicted in 2D). In addition, in male WT mice, a few kisspeptin expressing cells $(12.3 \%)$ in the RP3V were

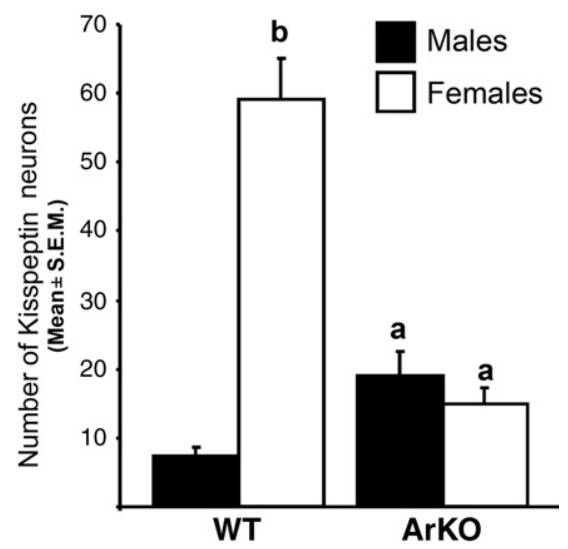

Fig. 1. Total number of kisspeptin expressing neurons (mean \pm SEM) present in the rostral periventricular area of the third ventricle (RP3V) of wildtype (WT) and aromatase knockout (ArKO) mice of both sexes. Significant differences are noted by a or $\mathrm{b}(P<0.05)$ compared to all other groups. 
WT

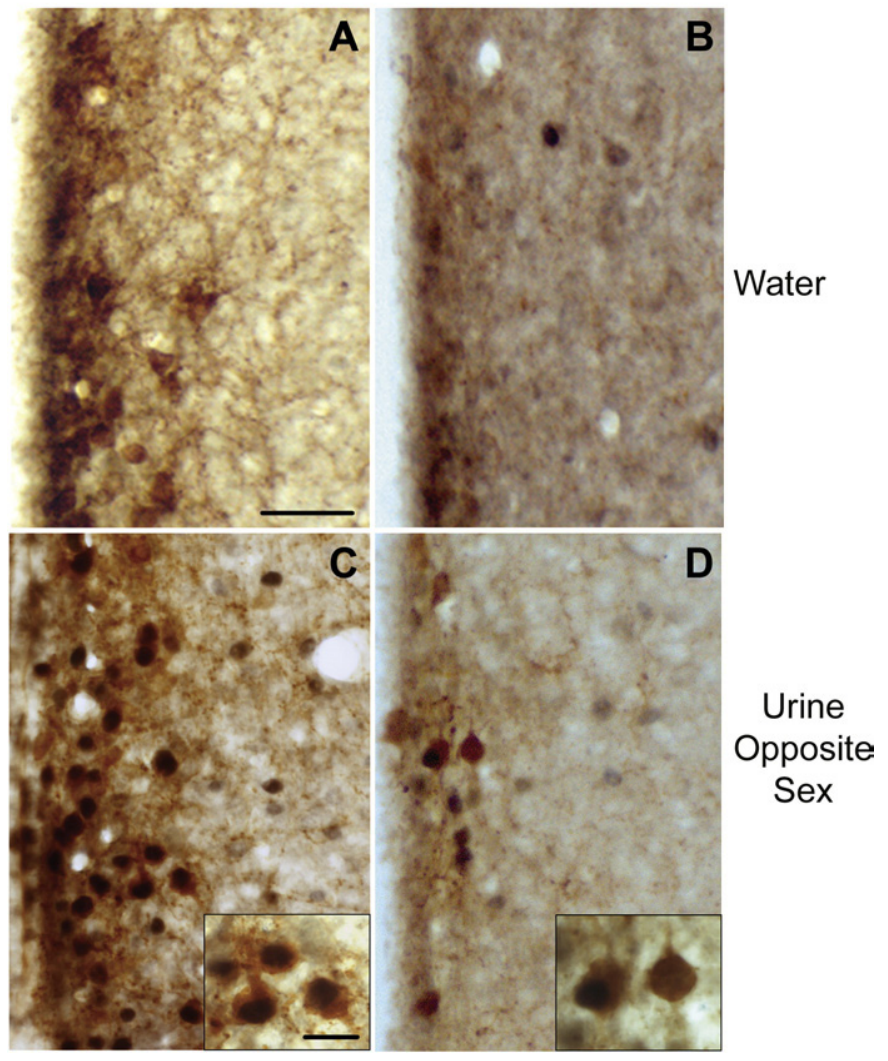

Fig. 2. Analysis of Fos activation in kisspeptin expressing neurons present in the RP3V. (A) depicts a detailed photomicrograph of the absence of fos activation in kisspeptinimmunoreactive neurons of a WT female exposed to water. (B) depicts a detailed photomicrograph of the absence of fos activation in Kisspeptin-immunoreactive neurons of an ArKO female exposed to water. (C) depicts a detailed photomicrograph of fos activation in kisspeptin-immunoreactive neurons of a WT female exposed to male urine. (D) demonstrates the activation of kisspeptin-immunoreactive neurons in an ArKO female after the exposure to male urine. In all pictures kisspeptin immunoreactive neurons are stained with DAB (brown precipitate) and fos-immunoreactive nuclei with DAB + Nickel (black precipitate). Scale bar in A represents $200 \mu \mathrm{m}$ and it is applicable to all photomicrographs. In (C), the bar in the detailed photomicrograph of the selected area represents $10 \mu \mathrm{m}$ and the same magnification was used in (D).

found to be co-labeled with Fos protein when exposed to estrous female urine. By contrast, this double-labeling was not observed in ArKO males exposed to estrous female urine (Fig. 3). This was
Table 1

Number of Fos-immunoreactive cells in non-kisspeptin neurons in the RP3V of WT mice exposed to either water, male urine or estrous female urine.

\begin{tabular}{llcl}
\hline Group/exposure & Water & Male urine & Female urine \\
\hline WT males & $20.5 \pm 12$ & $17.8 \pm 3.9$ & $19.4 \pm 4.8$ \\
WT females & $21.2 \pm 5.2$ & $49 \pm 7.7^{*}$ & $26.1 \pm 2.5$ \\
\hline
\end{tabular}

Values are expressed as mean \pm SEM.

* $P<0.05$ significantly different from all other groups.

confirmed by a three-way ANOVA revealing a significant effect of sex $(F(1,67)=8.83, P=0.01)$, type of urine exposure $(F(2,67)=18.11$, $P=0.0001)$, and a nearly significant genotype effect $(F(1,67)=2.01$, $P=0.09$ ). Furthermore, exposure to male urine activated kisspeptin neurons in females (Fig. 3 and 2C) but not those in males as seen from the significant sex by urine exposure interaction: $(F(2,67)=20.05$, $P=0.0001)$ and finally it had a greater effect in WT mice than in ArKO as revealed by the significant genotype by sex by urine exposure interaction $(F(2,67)=8.04, P=0.0007)$.

Post hoc analysis showed that exposure to male urine strongly activated kisspeptin expressing neurons in WT females in comparison to water $(P=0.0001)$ and estrous female urine exposure $(P=$ $0.0001)$. Activation by intact male urine also occurred in ArKO females (intact male urine vs. water: $P=0.002$; intact male urine vs. estrous female urine: $P=0.006$ ) but was dramatically reduced compared to WT females (percentage of activation following intact male urine exposure in WT vs. ArKO females: $P=0.0003$ ). In WT and ArKO males, exposure to intact male urine failed to activate kisspeptin expressing neurons in the RP3V. However, a small, but significant percentage of kisspeptin expressing neurons in the RP3V of WT males were activated following exposure to estrous female urine (WT males: water vs. estrous female urine: $P=0.017$ ), however this effect was not observed in ArKO males (KO males: water vs. estrous female urine: $P=0.58$ ).

In accordance with the sex difference observed in activation of kisspeptin-expressing cells by male urinary odors, a significant increase in number of Fos-immunoreactive cells in non-kisspeptin neurons was observed in the RP3V of WT females but not in that of WT males (Table 1). Furthermore, exposure to female urinary odors did not significantly increase the number of Fos-immunoreactive cells in non-kisspeptin neurons in the RP3V of WT males which is in line with the rather weak activation observed in kisspeptin cells by female odors. This was confirmed by statistical analysis with ANOVA indicating significant effect of $\operatorname{sex}(F(1,22)=7.09, P=0.01)$ and a significant sexy by type of urine exposure interaction $(F(2,22)=3.82$, $P=0.04)$.
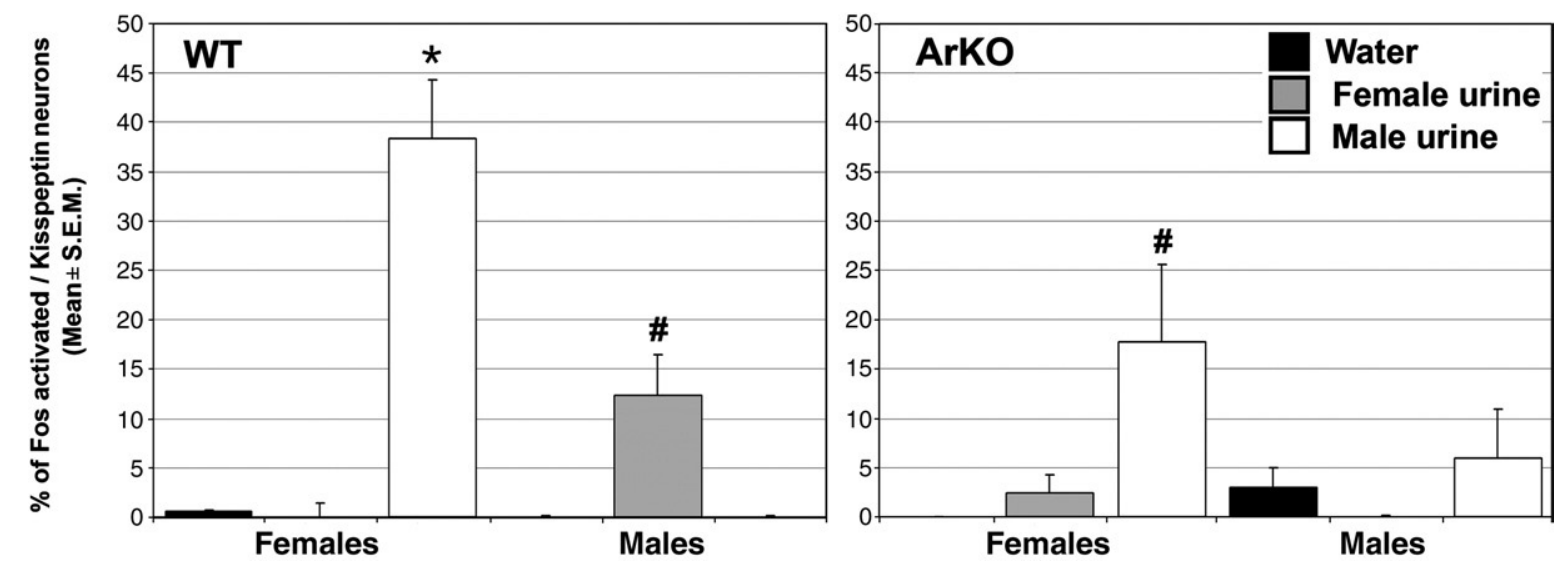

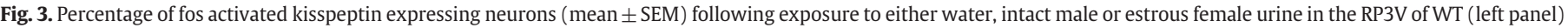

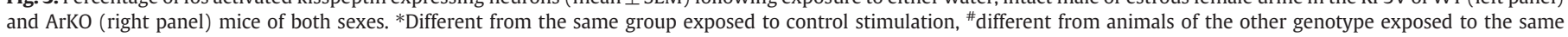
condition $P<0.05$ 


\section{Discussion}

In the present study we showed that opposite-sex but not samesex urinary odors activated kisspeptin expressing neurons in the RP3V in WT mice. Thus, male but not female urinary odors significantly activated RP3V kisspeptin neurons in female mice. By contrast, in male mice, we observed some activation of RP3V kisspeptin neurons after exposure to female but not male urinary odors. However, some caution is warranted with regard to the male data since only $12.3 \%$ of RP3V kisspeptin neurons showed Fos protein, which means in reality only 1 or 2 kisspeptin expressing neurons, which may question the biological significance of this result. Our findings are in line with the observation that only pheromones from opposite sex conspecifics induce sexually dimorphic responses in GnRH neurons in mice (Yoon et al., 2005) and consequently LH secretion (Coquelin and Bronson, 1979; Bronson and Desjardins, 1982; Bronson and Maruniak, 1976) and thus suggest that kisspeptin neurons in the RP3V may be part of the neural circuitry that relays information from the olfactory brain to the GnRH system in a sexually dimorphic manner. Furthermore, we showed that opposite-sex odors induced Fos in kisspeptin neurons in ArKO females, albeit significantly less than in WT females, suggesting that this activation by male pheromones does not depend on any organizational effects of estradiol on these kisspeptin neurons. By contrast, the sexual differentiation of the RP3V kisspeptin population was lost in ArKO mice, i.e. the number of kisspeptin expressing neurons was as low as what is observed in male ArKO (and WT) mice, suggesting organizational actions of estradiol on kisspeptin neuronal numbers in the female mouse.

\section{Pheromonal activation of kisspeptin neurons}

Several studies have shown that both volatile and non-volatile urinary odors can activate brain regions that regulate sexual behavior in both male and female mice (e.g., Keller et al., 2006a,b,c). For instance, in female mice, it has been shown that exposure to male odors activate several brain regions, including the medial amygdala, the bed nucleus of the stria terminalis, the medial preoptic area, and the ventromedial hypothalamus (Pierman et al., 2008). However, little is known about how such odors activate GnRH neurons leading to a neuroendocrine output. Here we provide new evidence that kisspeptin, which is a key upstream regulator of the GnRH system, is activated by opposite sex odors; nearly $40 \%$ of kisspeptin neurons showed Fos co-labeling in the RP3V of WT females after exposure to urine from intact males, thereby integrating sexually-relevant olfactory information into the reproductive system cascade. The percentage of kisspeptin neuronal activation observed in WT female mice after exposure to male urinary odors is very similar to what is observed at the time of the estradiol-progesterone-induced preovulatory LH surge (Gonzalez-Martinez et al., 2008).

The observation of some activation of kisspeptin neurons in the $\mathrm{RP} 3 \mathrm{~V}$ in WT males after being exposed to estrous female urine is in agreement with the previous finding that exposure to female pheromones induced phosphorylation of MAP-kinase in GnRH neurons (23\% of GnRH-1 neurons presented MAPK activation vs. $11 \%$ of activation in the control situation) (Yoon et al., 2005). However, as discussed above, this activation of kisspeptin neurons is low, only $12.3 \%$, as well as that the RP3V kisspeptin population is rather small in WT males ( $6.5 \pm 0.6$ neurons) which means that in reality 1-2 kisspeptin neurons were actually activated by female urinary odors. In this respect, it is interesting to note that exposure to female urinary odors using the same exposure paradigm as in the present study, failed to induce significant Fos responses throughout the olfactory pathway in male mice (Pierman et al., 2006). Since Fos is just one method for analyzing neuronal activation, it is also possible that other signaling pathways are activated in male mice following exposure to female odors. For example, we recently found that exposure to soiled bedding from estrous females rapidly (within $20 \mathrm{~min}$ ) induced MAPK phosphorylation in the medial amygdala (anterior and posterior) and the preoptic area in male mice (Taziaux et al., 2009). However, in that particular study, male subjects were gonadally intact, whereas in the present study, male subjects were castrated and treated with EB in adulthood to allow sex comparisons as well as to correct for the estrogen deficiency in ArKO males. It is thus possible that this particular hormone treatment is not ideal to observe any pheromonal activation on RP3V kisspeptin neurons in male mice.

Interestingly, kisspeptin neurons in the RP3V were still activated by male pheromones in ArKO females, although this activation was clearly reduced in comparison with WT females. ArKO females are infertile with underdeveloped uteri and ovaries lacking corpus lutea thus presenting a disruption of their ovarian cycles. Furthermore, ovulation could not be induced by treating gonadally intact ArKO females with EB between 4 and 8 weeks of age (Toda et al., 2001) suggesting that estrogens are necessary before week 4 after birth to show full reproductive function later. There may be a link between the reduced population of kisspeptin neurons as well as the reduced activation of these neurons by pheromones and their infertility, but clearly further studies are needed. A first logical step would be to determine whether an estradiol/progesterone treatment will activate kisspeptin and GnRH neurons in the RP3V and subsequently will induce a LH surge in ArKO females. These studies are currently under way.

\section{Sexual differentiation of kisspeptin neuronal number}

There is clear evidence that the number of kisspeptin neurons in the RP3V is sexually dimorphic in both rats and mice (Clarkson and Herbison, 2006; Kauffman et al., 2007) and that this differentiation between males and females probably reflects the perinatal actions of gonadal hormones. Classically it is thought that the male brain develops in the presence of testosterone and its estrogenic metabolite whereas the female brain develops in the absence of any hormonal secretions, i.e. by default. Accordingly, Kauffman and collaborators (2007) recently showed that a single injection with testosterone on the day of birth completely masculinized kisspeptin expression in female rats, suggesting again an active masculinization occurring in the male and perhaps a default organization in the female (Kauffman et al., 2007). However, the absence of a female-typical kisspeptin expression in female ArKO mice, despite being treated with EB for several weeks in adulthood, suggests an active contribution of estrogen to the feminization of this system during development (presumably pre-pubertal, before week 4 after birth). This is confirmed by the recent study by Clarkson et al (2009) showing that ovariectomy of female pups at postnatal $(\mathrm{P})$ day 15 resulted in a 70-90\% reduction in kisspeptin expression within the RP3V analyzed at either P30 or P60 whereas treatment with $17 \beta$-estradiol in P15ovariectomized mice from P15-30 or P22-30 resulted in a complete restoration of kisspeptin expression in this brain region. Furthermore, they showed decreased numbers of kisspeptin neurons in the RP3V of adult female ArKO mice, as was also observed in the present study. It should be noted that testosterone levels are increased in adult female ArKO mice (Fisher et al., 1998), although no data are available on testosterone levels during the early postnatal period. However, we have not observed any signs of any behavioral masculinization in ArKO females so far (Bakker et al., 2002b).

The finding of an effect of estradiol during the (early) postnatal period does not exclude the possibility of some prenatal hormonal events influencing the later development of kisspeptin expression. For instance, we recently observed that female alpha-fetoprotein knockout mice (AFP-KO) that carry a targeted mutation in the gene encoding an important fetal estrogen-binding protein, alpha-fetoprotein, and as a result were exposed to high levels of estrogens during embryonic 
development, had male-typical numbers of kisspeptin immunoreactive neurons in the RP3V (Gonzalez-Martinez et al., 2008). It should be noted that the postnatal development of AFP-KO females is normal, i.e. they are exposed to ovarian secretions as normal females, but somehow both their kisspeptin and GnRH neurons lose the ability to respond to ovarian estrogens since treatment with estradiol and progesterone failed to induce Fos protein in these neurons (also, they did not show a LH surge). These results suggest that estradiol during prenatal development induces a male-typical population of kisspeptin neurons in the RP3V. This result would be in line with the finding by Kauffman et al (2007) of testosterone on the day of birth inducing male-typical numbers of kisspeptin neurons. Furthermore, numbers of kisspeptin neurons were significantly higher in ArKO males compared to WT males, again suggesting that estradiol has masculinizing effects. Taken together the data obtained in ArKO mice in the present study as well as in AFP-KO mice in our previous study (Gonzalez-Martinez et al., 2008) indicate that estradiol can differentially affect the number of kisspeptin neurons depending on when during development the animal is exposed to estradiol: prenatal exposure to estradiol might lead to a male-typical expression whereas postnatal exposure to estradiol may lead to a female-typical expression of kisspeptin in the RP3V.

In summary we showed here that opposite-sex but not same-sex urinary odors activated kisspeptin expressing neurons in the RP3V of female mice thereby integrating this information into the reproductive axis. Furthermore, our results obtained in ArKO mice suggest that the ability of opposite-sex pheromones to activate kisspeptin neurons in WT females probably does not depend on the organizational action of estradiol, since ArKO females still show some Fos/kisspeptin coactivation in response to male urinary odors. By contrast, the sex difference in kisspeptin neuronal number in WT mice reflects an organizational action of estradiol in females, and perhaps to some extent in males as well.

\section{Acknowledgments}

We thank Mr. Quentin Douhard for his help in the animal handling. We thank Dr. Caraty for providing the kisspeptin antibody and Dr. Michael Baum for commenting on an earlier version of the ms. This work was supported by the following grants: Fonds National de la Recherche Scientifique (FNRS) (Mandat d'Impulsion Scientifique F.4502.07) and the NICHD (HD044897) to Dr Bakker. Dr. Bakker is a Research Associate of the FNRS. Sylvie Pierman was a FNRS research Fellow. Dr. González-Martínez was a Post-doctoral Researcher of the FNRS.

\section{References}

Adachi, S., Yamada, S., Takatsu, Y, Matsui, H., Kinoshita, M., Takase, K., Sugiura, $\mathrm{H}_{\text {, }}$ Ohtaki, T., Matsumoto, H., Uenoyama, Y., Tsukamura, H., Inoue, K., Maeda, K., 2007. Involvement of anteroventral periventricular metastin/kisspeptin neurons in estrogen positive feedback action on luteinizing hormone release in female rats. J. Reprod. Dev. 53, 367-378.

Bakker, J., Honda, S., Harada, N., Balthazart, J., 2002a. Sexual partner preference requires a functional aromatase (cyp19) gene in male mice. Horm. Behav. 42, 158-171.

Bakker, J., Honda, S., Harada, N., Balthazart, J., 2002b. The aromatase knockout mouse provides new evidence that estradiol is required during development in the female for the expression of socio-sexual behaviors in adulthood. J. Neurosci. 22, 9104-9112.

Baum, M.J., Keverne, E.B., 2002. Sex difference in attraction thresholds for volatile odors from male and estrous female mouse urine. Horm. Behav. 41, 213-219.

Boehm, U., Zou, Z., Buck, L.B., 2005. Feedback loops link odor and pheromone signaling with reproduction. Cell 123, 683-695.

Bronson, F.H., Desjardins, C., 1982. Endocrine responses to sexual arousal in male mice. Endocrinology 111, 1286-1291.

Bronson, F.H., Maruniak, J.A., 1976. Differential effects of male stimuli on folliclestimulating hormone, luteinizing hormone, and prolactin secretion in prepuberta female mice. Endocrinology 98, 1101-1108.

Bruce, H.M., 1959. An exteroceptive block to pregnancy in the mouse. Nature 184, 105

Clarkson, J., Herbison, A.E., 2006. Postnatal development of kisspeptin neurons in mouse hypothalamus; sexual dimorphism and projections to gonadotropinreleasing hormone neurons. Endocrinology 147, 5817-5825.
Clarkson, J., Boon, W.C., Simpson, E.R., Herbison, A.E., 2009. Postnatal development of an estradiol-kisspeptin positive feedback mechanism implicated in puberty onset. Endocrinology 150, 3214-3220.

Coquelin, A.F.H., Bronson, F.H., 1979. Release of luteinizing hormone in male mice during exposure to females: habituation of the response. Science 206, 1099-1101.

d'Anglemont de Tassigny, X., Fagg, L.A., Dixon, J.P., Day, K., Leitch, H.G., Hendrick, A.G., Zahn, D., Franceschini, I., Caraty, A., Carlton, M.B., Aparicio, S.A., Colledge, W.H., 2007. Hypogonadotropic hypogonadism in mice lacking a functional Kiss1 gene. Proc. Natl. Acad. Sci. U. S. A. 104, 10714-10719.

de Roux, N., Genin, E., Carel, J.C., Matsuda, F., Chaussain, J.L., Milgrom, E., 2003. Hypogonadotropic hypogonadism due to loss of function of the KiSS1-derived peptide receptor GPR54. Proc. Natl. Acad. Sci. U. S. A. 100, 10972-10976.

Dudley, C.A., Chakravarty, S., Barnea, A., 2001. Female odors lead to rapid activation of mitogen-activated protein kinase (MAPK) in neurons of the vomeronasal system. Brain Res. 915, 32-46.

Estrada, K.M., Clay, C.M., Pompolo, S., Smith, J.T., Clarke, I.J., 2006. Elevated Kiss-1 expression in the arcuate nucleus prior to the cyclic preovulatory gonadotrophinreleasing hormone/luteinizing hormone surge in the ewe suggests a stimulatory role for kisspeptin in oestrogen-positive feedback. J. Neuroendocrinol. 18, 806-809.

Fisher, C.R., Graves, K.H., Parlow, A.F., Simpson, E.R., 1998. Characterization of mice deficient in aromatase (ArKO) because of targeted disruption of the cyp19 gene. Proc. Natl. Acad. Sci. U. S. A. 95, 6965-6970.

Franceschini, I., Lomet, D., Cateau, M., Delsol, G., Tillet, Y., Caraty, A., 2006. Kisspeptin immunoreactive cells of the ovine preoptic area and arcuate nucleus co-express estrogen receptor alpha. Neurosci. Lett. 401, 225-230.

Franlyn, K.B.J., Paxinos, G., 1997. The Mouse Brain in Stereotaxic Coordinates. Academic Press, San Diego.

Gonzalez-Martinez, D., De Mees, C., Douhard, Q., Szpirer, C., Bakker, J., 2008. Absence of GnRH1 and Kiss1 activation in alpha-fetoprotein knockout mice: prenatal estrogens defeminize the potential to show preovulatory LH surges. Endocrinology $149,2333-2340$

Honda, S., Harada, N., Ito, S., Takagi, Y., Maeda, S., 1998. Disruption of sexual behavior in male aromatase-deficient mice lacking exons 1 and 2 of the cyp19 gene. Biochem. Biophys. Res. Commun. 252, 445-449.

Kang, N., Janes, A., Baum, M.J., Cherry, J.A., 2006. Sex difference in Fos induced by male urine in medial amygdala-projecting accessory olfactory bulb mitral cells of mice. Neurosci. Lett. 398, 59-62.

Kauffman, A.S., Gottsch, M.L., Roa, J., Byquist, A.C., Crown, A., Clifton, D.K., Hoffman, G.E., Steiner, R.A., Tena-Sempere, M., 2007. Sexual differentiation of Kiss1 gene expression in the brain of the rat. Endocrinology 148, 1774-1783.

Keller, M., Pierman, S., Douhard, Q., Baum, M.J., Bakker, J., 2006a. The vomeronasal organ is required for the expression of lordosis behaviour but not sex discrimination in female mice. Eur. J. Neurosci. 23, 521-530.

Keller, M., Douhard, Q., Baum, M.J., Bakker, J., 2006b. Destruction of the main olfactory epithelium reduces female sexual behavior and olfactory investigation in female mice. Chem. Senses 31, 315-323.

Keller, M., Douhard, Q., Baum, M.J., Bakker, J., 2006c. Sexual experience does not compensate for the disruptive effects of zinc sulfate-lesioning of the main olfactory epithelium on sexual behavior in male mice. Chem. Senses 31, 753-762.

Lloyd-Thomas, A., Keverne, E.B., 1982. Role of the brain and accessory olfactory system in the block to pregnancy in mice. Neuroscience 7, 907-913.

Lombardi, J.R., Vandenbergh, J.G., 1977. Pheromonally induced sexual maturation in females: regulation by the social environment of the male. Science 196, 545-546.

Meisel, R.L., Sachs, B.D., 1994. The physiology of male sexual behavior. In: Neill, J.D. (Ed.), The Physiology of Reproduction. Raven Press, New York, pp. 3-104.

Pankevich, D.E., Cherry, J.A., Baum, M.J., 2006. Accessory olfactory neural Fos responses to a conditioned environment are blocked in male mice by vomeronasal organ removal. Physiol. Behav 87, 781-788.

Patterson, M., Murphy, K.G., Thompson, E.L., Patel, S., Ghatei, M.A., Bloom, S.R., 2006. Administration of kisspeptin-54 into discrete regions of the hypothalamus potently increases plasma luteinising hormone and testosterone in male adult rats. J. Neuroendocrinol. 18, 349-354.

Pfaff, D.W., Schwartz-Giblin, S., McCarthy, M.M., Kow, L.M., 1994. Cellular and molecular mechanisms of female reproductive behaviors. In: Neill, J.D. (Ed.), The Physiology of Reproduction. Raven Press, New York, pp. 107-220.

Pierman, S., Douhard, Q., Balthazart, J., Baum, M.J., Bakker, J., 2006. Attraction thresholds and sex discrimination of urinary odorants in male and female aromatase knockout (ArKO) mice. Horm. Behav. 49, 96-104.

Pierman, S., Douhard, Q., Bakker, J., 2008. Evidence for a role of early oestrogens in the central processing of sexually relevant olfactory cues in female mice. Eur. J. Neurosci. 27, 423-431.

Simerly, R.B., 2002. Wired for reproduction: organization and development of sexually dimorphic circuits in the mammalian forebrain. Annu. Rev. Neurosci. 25, 507-536.

Taziaux M., Keller M., Balthazart J., Bakker J., 2009. Effect of aromatase inhibition on the rapid activation of phosphorylated mitogen-activated protein kinase (pMAPK) by sexual stimuli in the male mouse brain. Submitted for publication.

Toda, K., Okada, T., Takeda, K., Akira, S., Saibara, T., Shiraishi, M., Onishi, S., Shizuta, Y., 2001. Oestrogen at the neonatal stage is critical for the reproductive ability of male mice as revealed by supplementation with 17beta-oestradiol to aromatase gene (Cyp19) knockout mice. J. Endocrinol. 168, 455-463.

Whitten, W.K., 1959. Occurrence of anoestrus in mice caged in groups. J. Endocrinol. 18, 102-107.

Yoon, H., Enquist, L.W., Dulac, C., 2005. Olfactory inputs to hypothalamic neurons controlling reproduction and fertility. Cell 123, 669-682. 